Proceedings

\title{
Innovative Materials with Complex Applicability ${ }^{\dagger}$
}

\author{
Marta Ioana Moldoveanu *, Alexandra Olga Pintea and Daniela Lucia Manea \\ Department of Civil Engineering and Installations, Faculty of Civil Engineering, Cluj Napoca Campus, \\ Technical University of Cluj Napoca, Cluj-Napoca 400 114, Romania; Alexandra.Pintea@infra.utcluj.ro (A.O.P.); \\ Daniela.Manea@ccm.utcluj.ro (D.L.M.) \\ * Correspondence: Marta.Moldoveanu@ccm.utcluj.ro; Tel.: +4-0264-401-200 \\ + Presented at the 14th International Conference on Interdisciplinarity in Engineering-INTER-ENG 2020, \\ Târgu Mureș, Romania, 8-9 October 2020.
}

Published: 28 January 2021

\begin{abstract}
This article represents necessary research, adopting an interdisciplinary approach and a combination of methodologies, in order to better describe the evolution of the physical and mechanical characteristics of mortars. This was done employing modern methods and modern equipment, such as the Bohme equipment for wear tests. Compression and bending test equipment were also used, as well as methods for testing adhesion to the support layer. The purpose of this research is represented by the need to optimize mortar recipes, based on cement and organic and/or synthetic polymers. We focused on how they can be optimized in order to obtain recipes that best meet the needs of today's construction.
\end{abstract}

Keywords: polymers; casein powder; mechanical strength; mortar recipes; rubber powder; complex applicability

\section{Introduction}

As expected, the knowledge about mortars is scarce, due to the fact that each company holds on to its own recipe in order to capitalize its investment. Usually company recipes are patented. Not knowing the composition of mortar recipes based on cement and polymers available on the market, we set out to create new recipes. The Technical University of Cluj-Napoca, namely, the Construction Materials Department, has been involved in this type of research for several years already, testing different mortars with organic polymers and having obtained remarkable results in recent times.

\section{Materials and Methods}

With conventional methods we can describe only the physical-mechanical characteristics of materials. Modern investigation methods, however, describe the various processes that occur inside the structure of the materials, analyzing distribution and pore size. In our research for organic materials [1] (pp. 456-462), the return to the traditional methods of obtaining construction materials was considered.

The polymers were introduced in the standard recipe of cement mortars: organic (casein) $2 \%$ compared to the amount of cement. In the following, we will name each recipe with an abbreviation, so that we can easily identify them in the text and graphs. The abbreviations are as follows: Standard Mortar-MS; 2\% Casein Mortar-MC 2\%; 2\%, 5\%, and 10\% Rubber Powder Mortar-MPC 2\%, 5\%, and $10 \%, 2 \%, 5 \%$, and $10 \%$ Rubber Powder Mortar and Casein $2 \%-M P C 2 \%, 5 \%$, and $10 \% C 2 \%$.

The main objective of this article is to emphasize the contribution of polymers, in various forms, in mortar recipes [2] (pp. 37-40). Obtaining a mortar with an organic polymer recipe and also with a complex applicability is our goal. The research was performed using modern methods highlighting the contribution of polymers in increasing the physical and mechanical performance of the studied mortars. Along with our main objective, we also had these secondary objectives: 
- Analyzing the current situation regarding mortars and polymers used in construction.

- Making rubber mortar recipes with a concentration of $2 \%, 5 \%$, and $10 \%$ by weight of cement and testing them in order to determine their physical and mechanical characteristics.

- Making rubber mortar recipes with a concentration of $2 \%, 5 \%$, and $10 \%$ by weight of cement with an additional casein concentration of $2 \%$ by weight of cement. Investigating them by traditional methods and highlighting the contribution of casein.

- Determination of the physical and mechanical characteristics of the standard mortar and all mortar recipes, maintaining the standards in force, and also testing the mortar recipes at 3, 7, and 28 days.

Studying the chemical properties of cement by testing the standard mortar recipe, but also the organic and synthetic polymer mortar recipes at 3, 7, and 28 days, we can obtain results that will further our research.

The steps for the standard mortar recipe and testing equipment are shown in Figures 1-3. We can observe that every single component was carefully selected, measured, mixed, placed in proper sample boxes, depending on which testing was to follow, and, eventually, tested.

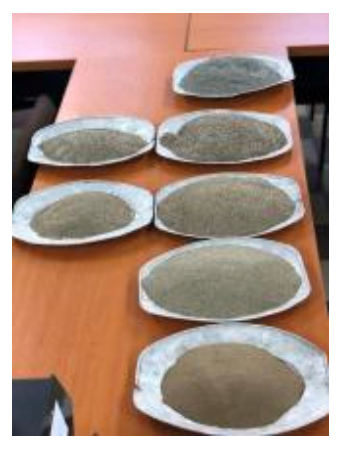

(a)

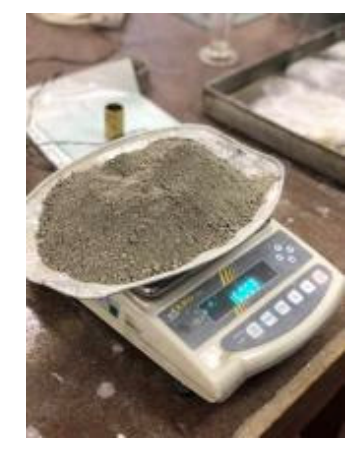

(b)

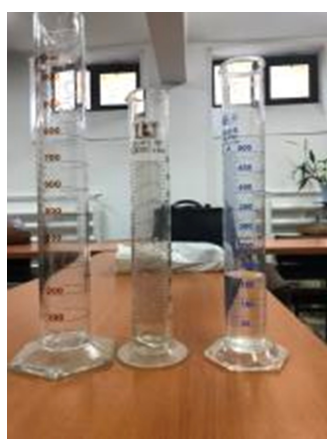

(c)

Figure 1. (a-c) Precise measuring of solid components.

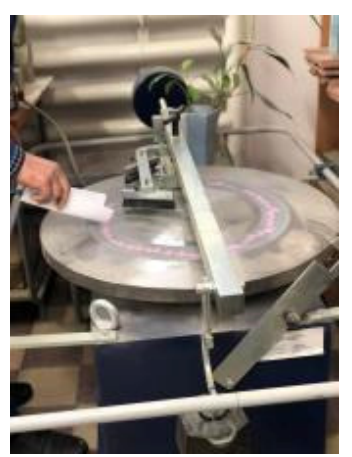

(a)

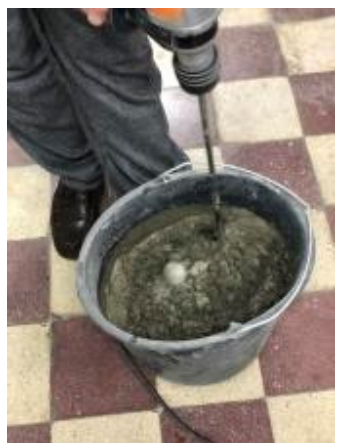

(b)

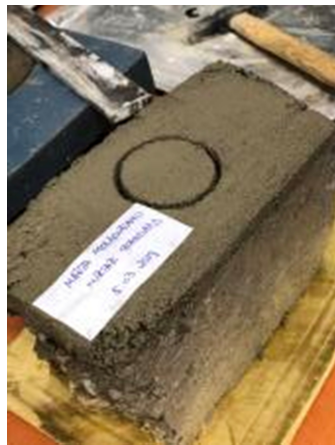

(c)

Figure 2. (a-c) Material preparation and Bohme equipment.

Step one is picking the right materials and precise measuring, as shown in Figure 1a-c. The higher the quality of the materials, the more qualitative the result will be, but in the field of construction, we must take into account another very important aspect—-the cost. 


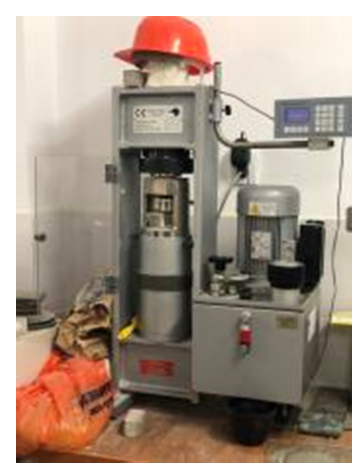

(a)

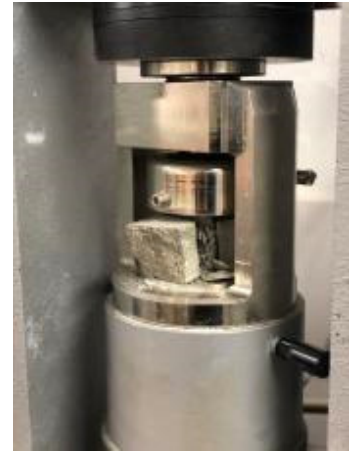

(b)

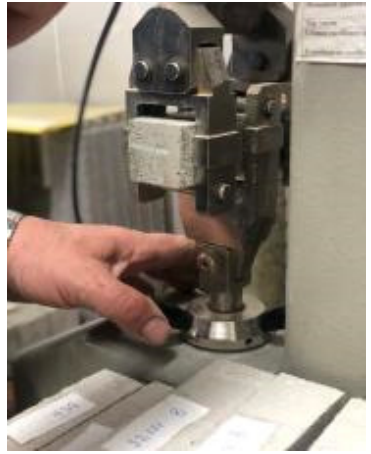

(c)

Figure 3. (a-c) Sample testing equipment.

The water concentration in the mortar recipe is very important because it dictates the consistency of the final result, therefore, it is very important to measure it carefully and with maximum accuracy, as shown in Figure $1 b$.

The next important step is mixing them together, as shown in Figure 2a, with the help of a mixer, so we can obtain a homogeneous compound. The material is usually tested with a testing cone.

Figure $2 b$ showcases the adhesion to the main substrate and in Figure $3 c$ we can see the equipment by which the compressive strength of the material sample is measured. Figure 3a highlights the bending equipment. In both situations, the material sample will break when the load is too high, thus establishing the maximum tolerability value. The pink abrasion sand is used for abrasion testing with the Bohme equipment. The Bohme equipment, as shown in Figure 2c, is in accordance with EN standards EN 1338, 1339, 1340, EN 13748-2, 13892-3, EN 14157. The machine is used to determine the volume loss of a sample subjected to the abrasion test.

Three standard mortar samples were prepared, which were tested for bending and compression, as we can see in Figure $3 a-c$, obtaining the results pointed out in Figure 4. The prepared samples for the bending and the compression tests are placed in $4 \times 4 \times 16 \mathrm{~cm}$ molds.

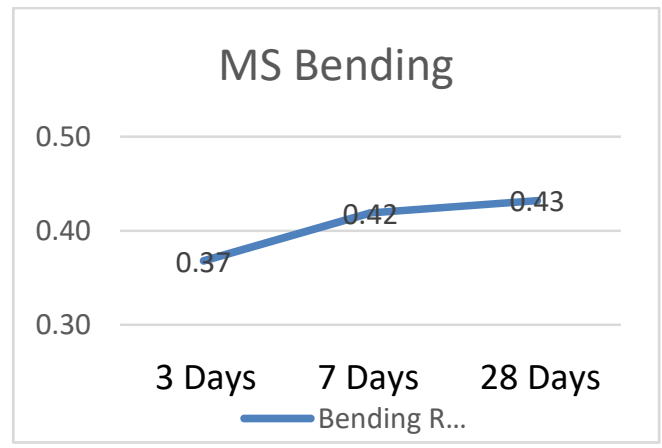

(a)

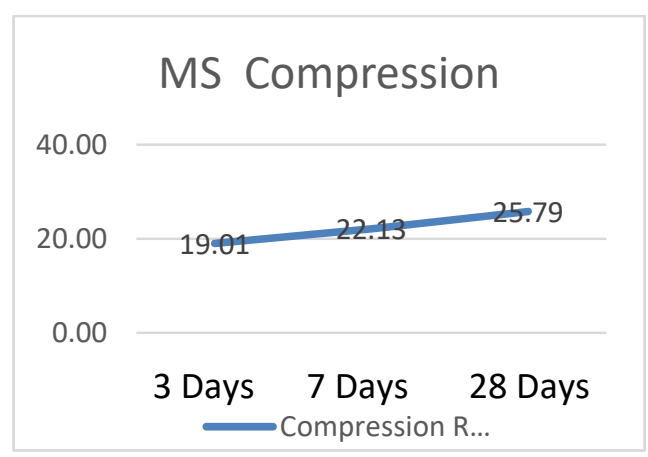

(b)

Figure 4. Three, 7 , and 28 day bending (a) and compression (b) tests for MS, $4 \times 4 \times 16$ samples.

\section{Results}

The results presented in Figure 4 highlight the evolution over time at 3, 7, and 28 days in terms of bending and compressive strength. One can easily observe the evolution of these values due to the hydration processes of the cement.

Figure 5a-d shows images from the adhesion testing of the standard mortar to the support layer (concrete element), which will represent future research directions. 


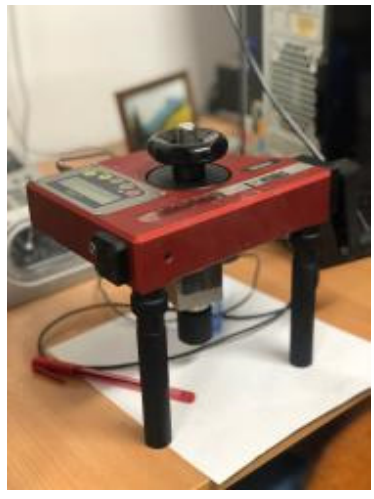

(a)

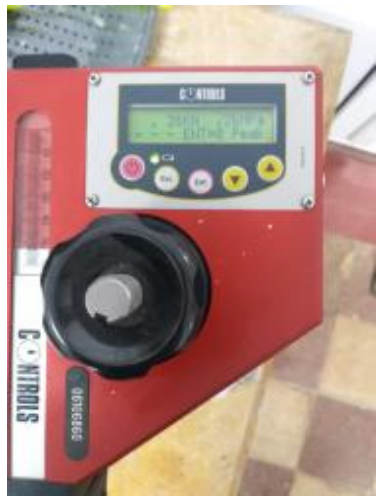

(b)

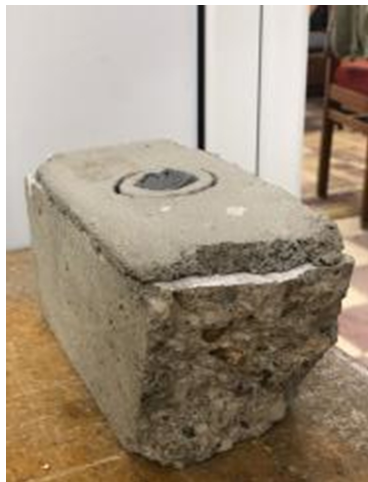

(c)

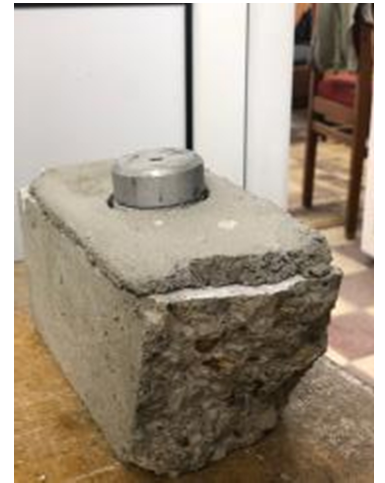

(d)

Figure 5. (a-d) Twenty-eight day adhesion test on the screed.

In order to improve the workability of a mortar, a natural polymer casein in a proportion of $2 \%$ by weight of cement [3] was added. Studying the specialty literature and studying the articles on the subject, it was found that the percentage of organic material used in researched recipes behaves best at a percentage of $2 \%$ [4]. Thus, we will discuss and later compare the recipes with $2 \%$, with the $5 \%$ and $10 \%$ only used as examples. Therefore, the experimental program involved the study of three samples of $4 \times 4 \times 16$, in which casein was introduced in a percentage of $2 \%$ of the overall amount of cement in the recipe of the initial standard mortar. Figure 6 calls attention to the results from the three test samples of standard mortar with $2 \%$ casein, namely $\mathrm{MC} \%$, using the equipment provided by the Technical University of Cluj-Napoca; namely, the bending test device and the hydraulic press. We will structure the abbreviations in Table 1 , in order to have better readability.

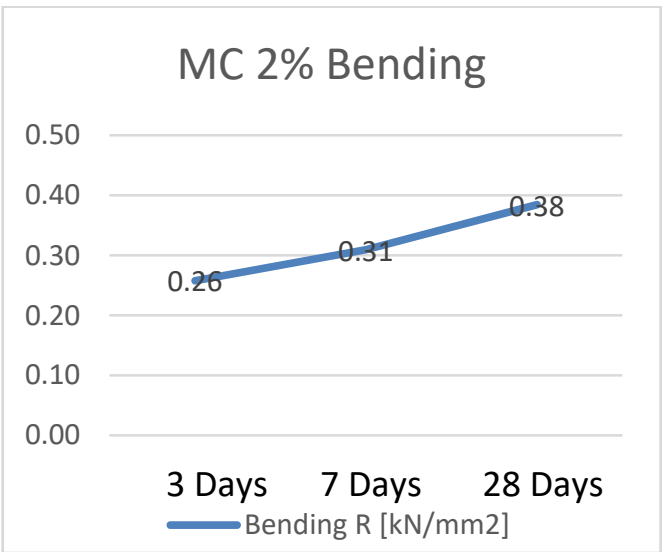

(a)

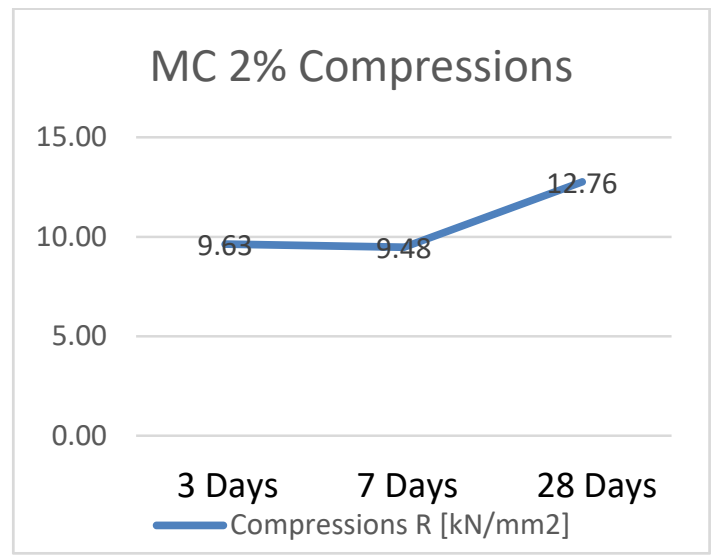

(b)

Figure 6. Three, 7, and 28 day bending (a) and compression (b) tests for MC2\%, $4 \times 4 \times 16$ samples.

Table 1. Mortar sample abbreviations.

\begin{tabular}{ccc}
\hline Abbreviation & Percentage & Detailing \\
\hline MS & $2-10 \%$ & Standard Mortar \\
MCx $\%$ & $2-10 \%$ & Standard Mortar with $\mathrm{x} \%$ Casein Polymer \\
MPCx $\%$ & $2-10 \%$ & Standard Mortar with $\mathrm{x} \%$ Rubber Powder and $\mathrm{x} \%$ Casein Polymer \\
$\mathrm{MPCx} \% \mathrm{Cy} \%$ & $2-10 \%$ & Standard Mortar with $\mathrm{x} \%$ Rubber Powder and $\mathrm{y} \%$ Casein Polymer \\
\hline
\end{tabular}

In the following study, we analyzed another three samples of $4 \times 4 \times 16$ in which casein and rubber powder were introduced in a percentage of $2 \%$ to $10 \%$ of the amount of cement (rubber powder) 
and a constant percentage of $2 \%$ of casein polymer [4]. Figure 7 shows the results from the three test samples of standard mortar with $2-10 \%$ rubber powder and $2 \%$ casein powder, namely, $\mathrm{MP} 2-10 \% \mathrm{C} 2 \%$.

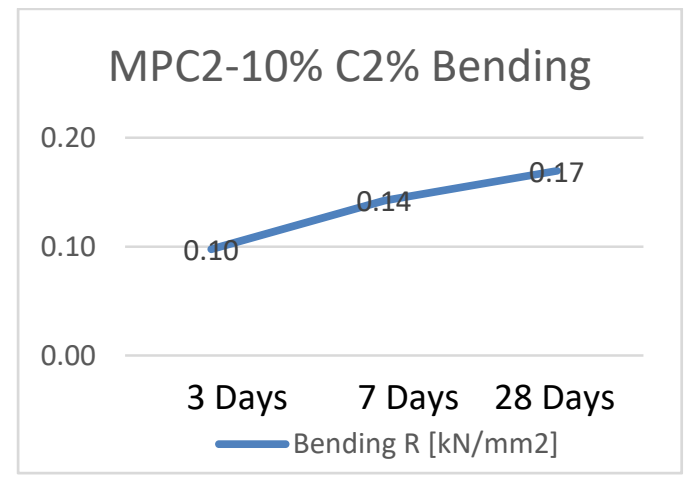

(a)

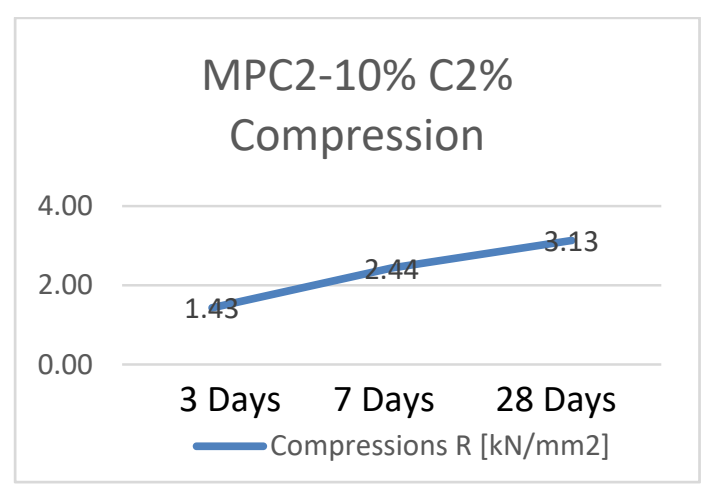

(b)

Figure 7. Three, 7, and 28 day bending (a) and compression (b) tests for MPC5-10\% C2\%, $4 \times 4 \times 16$ samples.

The results presented in Figure 7 highlight the evolution over time at 3, 7, and 28 days of bending strength and compressive strength for the rubber and casein powder mix recipe. Here we can see the evolution of these values due to the hydration processes of the cement and also the use of polymers increases the handling of the product [5].

\section{Conclusions}

The general conclusions of this paper, which summarizes all discussions on the methods of investigation used, as well as personal input on the subject, represents all the knowledge learned so far and all the tests done on the proposed mortar recipes, concerning the bending strength and compressive strength, the resistance to permeability [6], all those test were made in the Technical University of Cluj-Napoca labs [7,8].

As specific conclusions on the methods of investigation used [9], we can mention that as time passes, the standard mortar samples at 28 days are usually much more resistant to compression than 3 days old samples; this can be seen in Figure 4, Figure 6, and Figure 7. This happens with all recipes, as we can see in Figure 8. The comparison is made between the three types of recipes at the same time of measurement at odds with the standard mortar. What is noticeable is the fact that both the casein and the rubber powder and casein recipes are less resistant to compression and bending at 3 days, 7 days, and at 28 days, which is why the next stage of the research will involve recipes in which both polymers will not be used, but only one of them. We also propose a microscopic investigation, in order to study how the structure of the mortar evolves using these polymers. When comparing them, one can observe a better compressive strength of the mixed recipe of $10 \%$ rubber powder and $2 \%$ casein, also known as the abbreviation $\mathrm{MPC} 10 \% \mathrm{C} 2 \%$, compared to the benchmark-the standard mortar MS; the compressive strengths are completely different. Even with lower strength results, one thing stands out; namely, the fact that the handling was clearly superior through the use of polymers [10]. All research has been carried out in accordance with the relevant European standards [11-24].

We leave the discussions open, in terms of adhesion tests, as these will be performed on the support layer alongside the abrasion tests in the near future in one of our next research papers. The recipes with the related interpretations should not be neglected as they are very important towards obtaining a material with the minimum necessary mechanical strength, but with a superior resistance to permeability [6], which is of the utmost importance in terms of usage. 


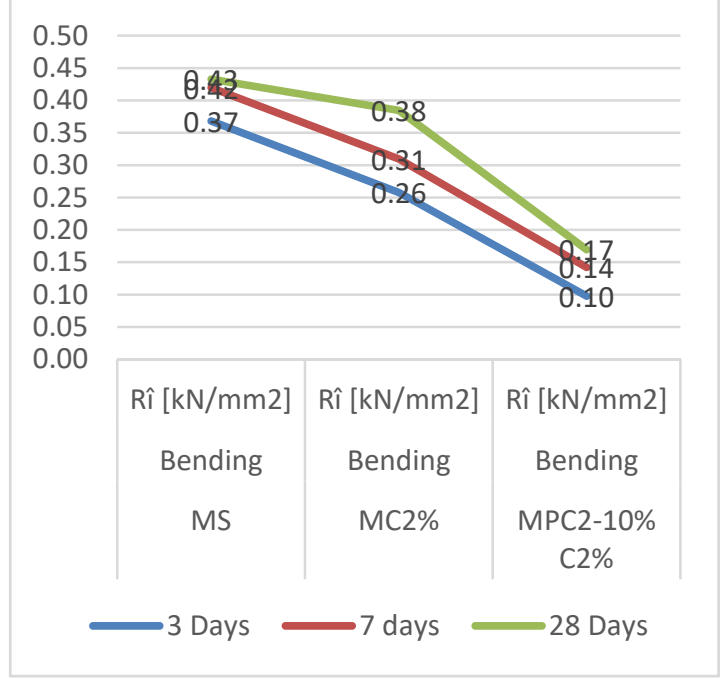

(a)

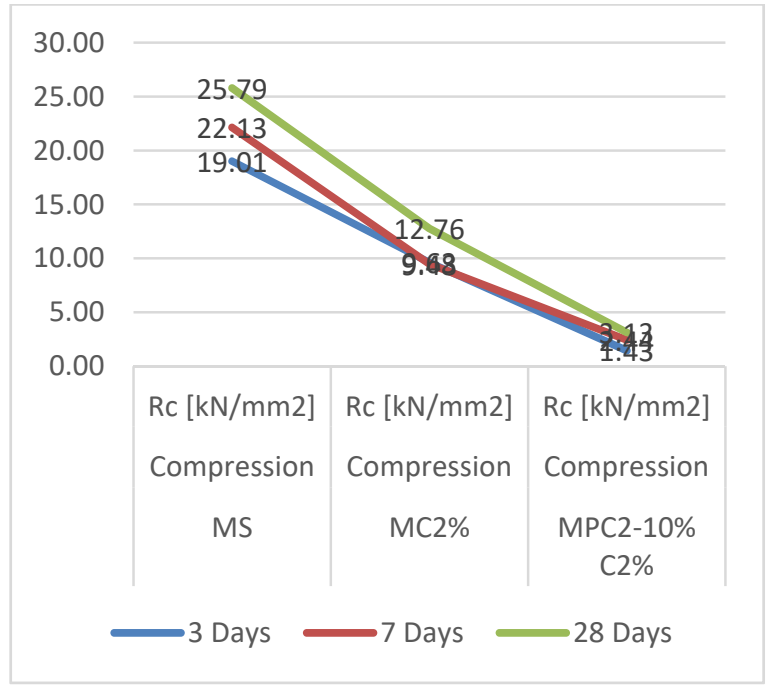

(b)

Figure 8. Three, 7, and 28 day bending and compression tests for MS, MC2\%, and MPC5- $10 \% \mathrm{C} \%$, $4 \times 4 \times 16$ samples.

\section{References}

1. Cantor (Andres), D.M.; Manea, D.L. Innovative building materials using agricultural waste. Proc. Technol. 2015, 19, 456-462. [CrossRef]

2. Saikhede, S.R.; Satone, S.R. An Experimental Investigation of Partial Replacement of Cement by Various Percentage of Phosphogypsum and Flyash in Cement Concrete. Int. J. Eng. Res. Appl. 2014, 4, 37-40.

3. Jumate, E.; Manea, D.L.; Moldovan, D.; Fechete, R. The effects of Hydrophobic Redispersibile Powder Polymer in Portland Cement Based Mortars. Proc. Technol. 2017, 181, 316-323.

4. Pintea, A.O.; Daniela Manea, D.L. Influence of Natural Polymers upon Cement-Based Plastering Mortars. In Proceedings of the C65 International Conference, Cluj-Napoca, Romania, 15-17 November 2018.

5. Pintea, A.O.; Manea, D.L. New types of mortars obtained by aditiving traditional mortars with natural polymers to increase physico-mechanical performances. In Proceedings of the International Conference INTER-ENG 2018, Targu Mures, Romania, 4-5 October 2018.

6. Pintea, A.O.; Manea, D.L. Influence of Natural Organic Polymers upon Plaster Mortar Workability. In Proceedings of the International Conference INTER-ENG 2019, Targu Mures, Romania, 3-4 October 2019.

7. EN 934-6:2002/A1:2006 Additives for Concrete, Mortar and Paste. Part 6: Sampling, Control and Conformity Assessment. Available online: https://vdocuments.site/sr-en-934-2-aditivi-pentru-beton.html (accessed on 29 November 2020).

8. EN 13139:2003 Aggregates for Mortars. Available online: https://standards.iteh.ai/catalog/standards/cen/ d1169c31-b23e-41fa-8f1d-cf3a9b0ce8dd/en-13139-2002 (accessed on 29 November 2020).

9. STAS 790-1984 Water for Mortars and Concretes. Available online: https://magazin.asro.ro/ro/standard/21638 (accessed on 29 November 2020).

10. EN 196-1:2016 Methods of Testing Cement. Determination of Strength. Available online: https://www.en-standard. eu/bs-en-196-1-2016-methods-of-testing-cement-determination-of-strength/ (accessed on 29 November 2020).

11. EN 196-2:2013 Method of Testing Cement. Chemical Analysis of Cement. Available online: https://standards.iteh. ai/catalog/standards/cen/47283941-90a2-43dc-8b2c-dea6208712a6/en-196-2-2013 (accessed on 29 November 2020).

12. EN 196-3:2016 Methods of Testing Cement Determination of Setting Times and Soundness. Available online: https://standards.iteh.ai/catalog/standards/cen/e4921eca-8101-4261-b066-25d19b9b8e8a/en-196-32016 (accessed on 29 November 2020).

13. EN 196-4:2007 Methods of Testing Cement. Quantitative Determination of Constituents. Available online: https://standards.iteh.ai/catalog/standards/cen/d55093fb-4c58-46c6-a91c-150121867625/cen-tr-1964-2007 (accessed on 29 November 2020). 
14. EN 196-6:2018 Methods of Testing Cement. Determination of Fineness. Available online: https://standards.iteh.ai/ catalog/standards/cen/9feaed91-485e-4e0b-93c6-36357e1580ec/en-196-6-2018 (accessed on 29 November 2020).

15. EN 197-1:2001. Cement Part 1. Composition, Specifications and Conformity Criteria for Common Cements. Available online: https://standards.iteh.ai/catalog/standards/sist/00e7c857-98b1-4132-b9ec-9cf156a8dfc3/sisten-197-1-2001-opra2-2006 (accessed on 29 November 2020).

16. EN 197-2:2020 Cement-Part 2: Assessment and Verification of Constancy of Performance. Available online: https://standards.iteh.ai/catalog/standards/cen/49c9299e-9123-42eb-92d2-19b6461f41ad/en-197-22020 (accessed on 29 November 2020).

17. EN 197-3:2001 Cement-Part 3: Composition, Specifications and Conformity Criteria for Low Heat Common Cements. Available online: https://standards.globalspec.com/std/1347120/din-en-197-3 (accessed on 29 November 2020).

18. EN 197-4:2004 Cement. Composition, Specifications and Conformity Criteria for Low Early Strength Blastfurnace Cements. Available online: https://standards.iteh.ai/catalog/standards/cen/83a154a8-c2fc-4b4aa408-8b46d6834132/en-197-4-2004 (accessed on 29 November 2020).

19. EN 197-5:2000. Cement. Part 5. Portland-Composite Cement CEM II/C-M and Composite Cement CEM VI. Available online: https://standards.iteh.ai/catalog/standards/cen/69d3b559-4114-43b3-bfed-05787fc839a2/ pren-197-5 (accessed on 29 November 2020).

20. EN 1338:2003 Concrete Paving Blocks. Requirements and Test Methods. Available online: https://standards. iteh.ai/catalog/standards/cen/c0ceb4fd-ff66-437d-b05c-c62974d4ab41/en-1338-2003-ac-2006 (accessed on 29 November 2020).

21. EN 1339:2003 Concrete Paving Flags. Requirements and Test Methods. Available online: https://standards. iteh.ai/catalog/standards/cen/19c0de8e-9430-4961-8d97-a1c6b70d041c/en-1339-2003-ac-2006 (accessed on 29 November 2020).

22. EN 1340:2003 Concrete Kerb Units. Requirements and Test Methods. Available online: https:// standards.iteh.ai/catalog/standards/cen/84647ce9-386d-4a39-8406-47d56f64692b/en-1340-2003 (accessed on 29 November 2020).

23. EN 13748-2 Terrazzo Tiles Part 2: Terrazzo Tiles for External Use. Available online: https://standards.iteh.ai/ catalog/standards/cen/db14b22d-212a-4aba-916f-62f32cf64bbe/en-13748-2-2004 (accessed on 29 November 2020).

24. EN 14157:2017 Natural Stone Test Methods. Determination of the Abrasion Resistance. Available online: https: //standards.iteh.ai/catalog/standards/cen/248b629a-b8ea-4c98-9554-0a5c2355def2/en-14157-2017 (accessed on 29 November 2020).

Publisher's Note: MDPI stays neutral with regard to jurisdictional claims in published maps and institutional affiliations.

(C) 2021 by the authors. Licensee MDPI, Basel, Switzerland. This article is an open access article distributed under the terms and conditions of the Creative Commons Attribution (CC BY) license (http://creativecommons.org/licenses/by/4.0/). 